\title{
Rare presentation of a testicular angiofibroma treated with testis sparing surgery
}

\author{
Luca Leone $^{1}$, Paola Fulvi ${ }^{1}$, Giulia Sbrollini ${ }^{1}$, Alessandra Filosa ${ }^{2}$, Enrico Caraceni ${ }^{3}$, \\ Angelo Marronaro ${ }^{3}$, Andrea B. Galosi ${ }^{1}$ \\ ${ }^{1}$ Clinica Urologica, Scuola di Specializzazione in Urologia, Università Politecnica delle Marche, Ancona, Italy; \\ ${ }^{2}$ UOC Urologia Civitanova Marche, AV 3, ASUR Marche, Italy; \\ ${ }^{3}$ Anatomia Patologica, AV 3, ASUR Marche, Italy.
}

\begin{abstract}
Summary Introduction: Testicular benign tumors are very rare (<5\%). Testicular Angiofibroma $(A F)$ is one of those, however the gold standard of treatment and follow-up is still unclear.

Case report: A 47 years-old man with only one functioning testis was referred to our clinic for a palpable right testicular mass and atrophic contralateral testis. Patient underwent testis-sparing surgery with inguinal approach and intraoperative frozen sections examination with diagnosis of AF.

Final histology confirmed AF. Post-operative follow-up was uneventful. Clinical and ultrasonographic follow-up was negative after 8 months.

Conclusion: We report a conservative surgery in a patient with AF of the solitary testis. AF is a benign para-testicular fibrous neoplasm that could be misinterpreted as malignant tumor and treated with orchiectomy. Testis-sparing surgery is recommended in this case with intraoperative pathological examination. The excision of the mass is enough but in front of a possible recurrence a long follow-up is advisable.
\end{abstract}

KEY WORDS: Testicular neoplasms; Angiofibroma; Testis-sparing surgery; Small testicular tumors.

Submitted 15 November 2016; Accepted 15 December 2016

\section{INTRODUCTION}

Angiofibroma (AF) is a benign neoplasm arising mainly in vulvo-vaginal region in woman and in inguino-scrotal region in men; it is very rare in male genitalia (1). Because of the variability of clinic findings and uncertain classification, the gold standard of treatment and followup are still unclear. Testis-sparing surgery (TSS) with intraoperative frozen sections of small testicular lesions is recommended (2) to avoid over-treatment of benign tumors like AF, despite those are uncommon.

We present a case of an AF in a young man with an only one functioning testis.

\section{Case report}

A 47 years old man was referred to our department for a palpable and painless right testicular mass found incidentally during a shower. The left testis was atrophic because of a torsion at age of 15 . He had not further previous medical or surgical history. Tumor markers (alpha- fetoprotein, human chorionic gonadotropin, lactate dehydrogenase) were normal.

The ultrasonography described an $1.1 \mathrm{~cm}$ isoechoic nodule of the right testis with extratesticular growth located in the upper third, associated with thinning of the scrotal sac and a moderate hydrocele; a posterior acoustic shadowing behind the lesion was evident, suggesting the presence of fibrous tissue in the mass (Figures 1-2).

Patient underwent inguinal approach with externalization of right testis. The lesion appeared superficial, firmly attached to the tunica albuginea (Figure 3).

Considering that patient was monorchid, it was performed a testis-sparing surgery of the lesion using an enucleation technique plus biopsies of the surrounding parenchyma. At the frozen section a fibrous benign lesion was found. The wound was closed. Definitive his-

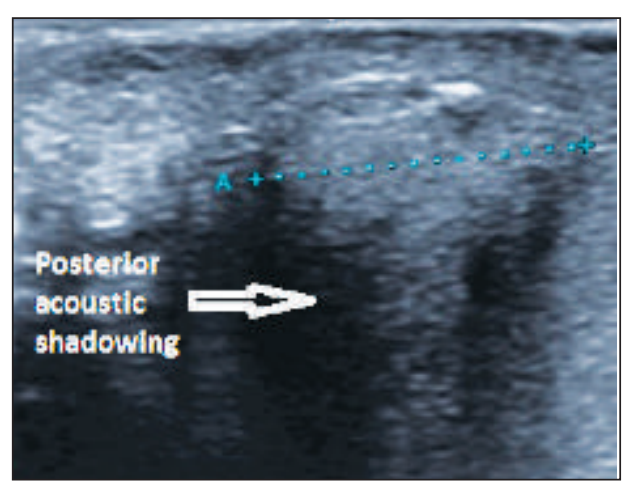

Figure 1.

Testicular mass at ultrasonography.

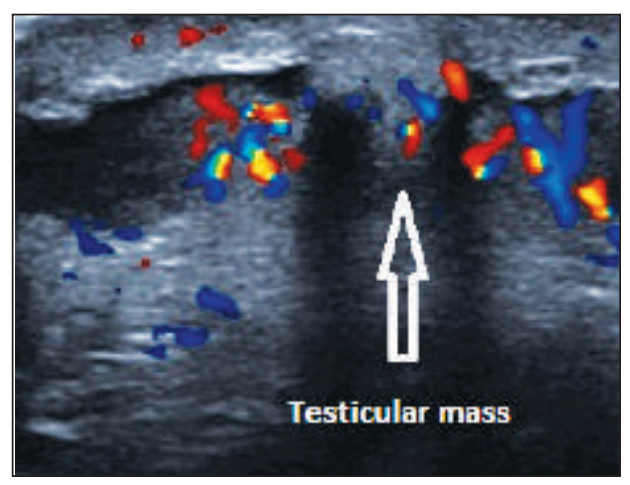

Figure 2.

Testicular mass at colorDoppler. 


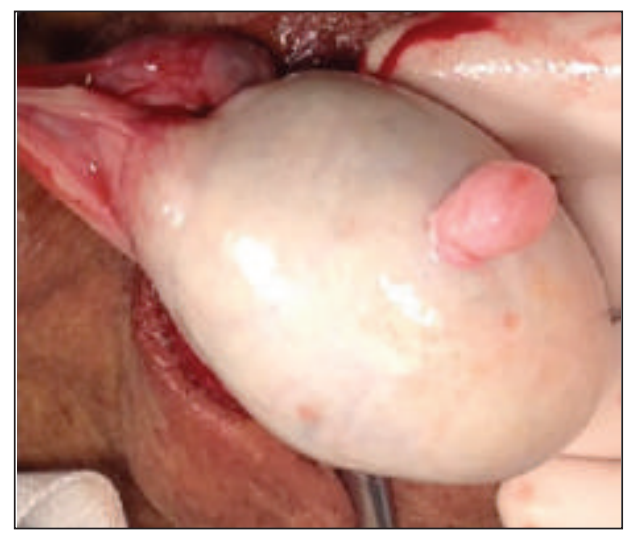

Figure 3. Intra-operative picture of the testicular mass.

tological examination confirmed the AF. Any complication was observed in the post-operative time. Clinic and ultrasonographic follow-up after 3 and 8 months was negative for recurrence.

\section{Discussion}

Testicular and para-testicular benign fibromatous lesions are rare, arise in most cases from tunica vaginalis and the $15 \%$ of cases from tunica albuginea (like this one) $(2,3)$. The aetiology is uncertain: while some authors consider them non-neoplastic and reactive process, others consider them true neoplasms arising from the cellular tunics if inflammatory cells are not present; these lesions can arise from the testis (fibromas of gonadal stromal origin) or from testicular tunics (3).

In particular, angiomyofibroblastoma-like (AMF-like) tumors are benign mesenchymal neoplasm with extremely low incidence (4), initially described in women by Nucci et al. (5), and then in men by Laskin et al. (6). Iwasa concluded that cellular AF and AMF-like tumors are very similar but they differ in the stroma/cellular ratio in favour of $\mathrm{AF}$ (7). No cases of metastatic disease or recurrence are described (8).

AF arises mainly in inguino-scrotal region in men but is very rare in the testis; it originates from perivascular stem cells that differentiates into fatty and myofibroblastic cells (9); it is composed by prominent blood vessels, low cellularity with spindle cells (9) within collagenous stroma, without mitotic activity, necrosis, nuclear pleomorphisms. Testicular parenchyma is not remarkable inside the lesion and a vascular axis is described in the center. The histological differential diagnosis includes aggressive angiomyxoma, angiomyofibroblastoma, spindle cell lipoma, solitary fibrous tumor, perineurioma and leiomyoma (5).

The ultrasonography findings of these lesions are not frequently described, and there is a large variation of characteristics: fibromatous tumors are described as hyper- or iso- or hypoechoic, with or without posterior acoustic shadowing (10). In some paper are described also magnetic resonance imaging (MRI) findings: are lesions with intermediate signal intensity in all sequences, more hypointense on T2- than in T1- weighted sequences and failed to enhance after gadolinium administration (10). The differentiation of an inflammatory fibrous pseudotumor from a true neoplasm is based on clinical, radi- ographic, gross and microscopic features. Clinical and ultrasonography features (as the appearance of extratesticular masses) may indicate the benignity of the lesion, but the specificity isn't sufficient to permit confident differentiation between benign and malignant process; therefore, a histological evaluation of the lesion is mandatory.

Testis-sparing surgery is indicated in selected cases (bilateral testicular tumor or monorchid patient) (11); in cases of endophytic masses intraoperative ultrasound (IU) and collaboration with the pathologist can help to detect and enucleate the entire lesion (12); in this case a wedge resection was performed without IU because tumor was mostly exophytic and margins were clearly detectables.

The major concern for TSS is the small size of lesions send for frozen sections: the low quantity of tissue and the missing of intraoperative immunoistochemistry can affect the diagnosis $(1,13)$. The definitive histologic report is the only one to comply the final diagnosis.

Follow-up is still important also if the diagnosis is a benign tumor. We don't have many data in literature about follow-up of these lesions, because are very rare and most of papers report only a case report, like our experience; in the largest case series published composed by 40 (1) and 9 (3) men were negative for recurrence. Best strategy for testicular follow-up is ultrasound, because the sensibility for small and not palpable lesions.

\section{Conclusions}

Frozen sections are recommended in case of TSS that is an effective treatment for small testicular lesions to avoid over-treatment, limiting functional outcomes in cases of benign tumor, mostly in monorchid patients. Further studies and biggest series are needed to confirm the right follow-up to detect any recurrence.

\section{RefEREnCES}

1. Iwasa Y, Fletcher CD. Cellular angiofibroma: Clinicopathologic and immunohistochemical analysis of 51 cases. Am J Surg Pathol. 2004; 28:1426-35

2. Jones MA, Young RH, Scully RE. Benign fibromatous tumors of the testis and paratesticular region. A report. Am J Surg Pat. 1997; 21:296-305.

3. Jones MA, Young RH, Scully RE. Benign fibromatous tumor of the testis and paratesticular region: a report of 9 cases with a proposed classification of fibromatous tumors and tumor-like lesions. Am J Surg Pathol. 1997; 21:296-305.

4. Galosi AB, Scarpelli M, Mazzucchelli R, et al. Adult primary paratesticular mesenchymal tumors with emphasis on a case presentation and discussion of spermatic cord leiomyosarcoma. Diagnostic Pathology. 2014, 9:90.

5. Nucci MR, Granter SR, Flecther CD. Cellular angiofibroma: a benign neoplasm distinct from angiomyofibroblastoma and spindle cell lipoma. Am J Surg Pathol. 1997; 21:636-44.

6. Laskin WB, Fetsch JF, Mostofi FK. Angiomyofibroblastoma-like tumor of the male genital tract: Analysis of 11 cases with comparison to female angiomyofibroblastoma and spindle cell lipoma. Am J Surg Pathol. 1998; 22:6-16. 
7. Canales BK, Weiland D, Hoffman N, et al. Angiomyofibroblastoma-like tumors (cellular angiofibroma). Int J Urol. 2006; 13:177-9.

8. Maciel de Lima M jr, Maciel de Lima, Granja F. Angiofibroma testicular - A case report. Int J Med Phar Sci. 2014; 4:01-03.

9. Miyajima K, Hasegawa S, Oda Y, et al. Angiomyofibroblastomalike tumor (cellular angiofibroma) in the male inguinal region. Radiat Med. 2007, 25:173-177.

10. Sadowski EA, Salomon CG, Wojcik EM, Albala D. Fibroma of the testicular tunics. J Ultrasound Med. 2001; 20:1245-1248.
11. Sbrollini G, Mazzaferro D, Ettamimi A, et al. Diagnostic-therapeutic pathway for small lesions of the testis. Arch Ital Urol Androl. 2014; 86:397-399.

12. Fabiani A, Filosa A, Fioretti F, et al. Diagnostic ultrasound-guided excisional testicular biopsy for small $(<1 \mathrm{~cm})$ incidental nodules. A single institution experience. Arch Ital Urol Androl. 2014; 86:373-377.

13. Borghesi M, Brunocilla E, Schiavina R, et al. Role of testis sparing surgery in the conservative management of small testicular masses: oncological and functional perspectives. Actas Urol Esp. 2015; 39:57-62

\section{Correspondence}

Luca Leone, MD

luca.leone.1985@gmail.com

Paola Fulvi, MD

paola.fulvi19@gmail.com

Giulia Sbrollini, MD

giuliasbrollini@libero.it

Andrea B Galosi, MD (Corresponding Author)

galosiab@yahoo.it

Clinica Urologica, Scuola di Specializzazione in Urologia,

Università Politecnica delle Marche Ancona, Italy

Alessandra Filosa, MD

UOC Urologia Civitanova Marche, AV 3, ASUR Marche

Civitanova Marche, Italy

Enrico Caraceni, MD

ecarace@libero.it

Angelo Marronaro, MD

ang6marr@yahoo.it

Anatomia Patologica, AV 3, ASUR Marche, Italy 